\title{
AVALIAÇÃO FORMATIVA: EXPERIÊNCIAS NA FORMAÇÃO EM HISTÓRIA*
}

\author{
Douglas Mota Xavier de Lima
}

Ao ingressar na Universidade Federal do Oeste do Pará (Ufopa), em 2014, e lecionar regularmente as disciplinas História Antiga, História Medieval e História Moderna, componentes marcadamente voltados a conteúdos factuais e historiográficos, foram uma constante a adoção de aulas expositivas, a ênfase em discussões historiográficas e a formulação de avaliações escritas centradas em conteúdos factuais/conceituais. No entanto, a percepção, após os primeiros semestres, foi de que o cumprimento integral do programa da disciplina a partir dessa metodologia não estava resultando em melhor aprendizagem e, em sentido mais amplo, não estava contribuindo significativamente para a formação profissional dos alunos como professores. Paralelamente, problemas comuns do ambiente da sala de aula e da educação nos diferentes níveis do ensino, como o desinteresse dos alunos, a falta de leitura, a dificuldade na compreensão dos textos etc., apresentavam-se cada vez mais no cotidiano das disciplinas. Tal situação requereu mudanças, e estas começaram pela gradativa incorporação das proposições de ensino-aprendizagem, que pressupõem que o estudante deve ter papel mais ativo na construção de suas aprendizagens. Nesse sentido, passo a apresentar algumas reflexões e exemplos acerca de um aspecto em especial, a avaliação, tendo como base a experiência vivenciada no curso de licenciatura em história da Ufopa entre 2014 e 2018.

\section{A formação inicial do professor de história}

Considera-se que a formação inicial nas graduações de licenciatura em história é o momento ímpar no qual os saberes históricos e pedagógicos são mobilizados, problematizados, sistematizados e incorporados à experiência de construção do saber docente, bem como o momento de estruturação da identidade pessoal e profissional do professor. Todavia, a formação docente no Brasil

${ }^{*}$ DOI - 10.29388/978-65-86678-64-2-0-f.53-68

1 Bacharel e licenciado (2009) em História pela Universidade Federal Fluminense (UFF). Mestre (2012) e doutor (2016) em História Social pelo Programa de Pós-graduação em História da UFF. Professor adjunto da Universidade Federal do Oeste do Pará (Ufopa), atuando nas áreas de História Antiga, História Medieval e História Moderna. 
- o que pode ser ampliado a mais áreas do que apenas a da história — foi marcada pelo modelo da racionalidade técnica e científica, modelo generalizado pela fórmula "três + um", que consiste em, nos três primeiros anos, os alunos cursarem disciplinas obrigatórias da área de história e, em seguida, disciplinas obrigatórias da área de pedagogia, aplicando os conhecimentos na prática de ensino. Desse modo, durante as últimas décadas do século XX, predominou o modelo de formação que combinava licenciaturas curtas e plenas, de um lado, e bacharelados, de outro, estruturados com base na dicotomia entre conhecimentos específicos da disciplina e conhecimentos pedagógicos, entre preparação para o ensino e preparação para a pesquisa, e entre conhecimentos teóricos e prática (Fonseca, 2003, p. 60-62; Monteiro, 2013, p. 26-28).

Acrescenta-se a tais desafios o impasse institucional sobre a quem cabe formar professores. Tal problemática também tem estado em voga nas discussões internacionais e desdobra-se em outras questões, orientando investigações sobre a desarticulação entre as disciplinas pedagógicas e de conteúdo específico; o predomínio do conteúdo factual em detrimento de saberes curriculares e relativos às práticas pedagógicas; a resistência à discussão sobre ensino de história nas universidades de maior prestígio; e a separação entre a cultura histórica e a didática da história (Oliveira e Freitas, 2013).

Ana Maria Monteiro (2013) lembra que é comum encontrar críticas à formação recebida por parte dos professores de história, principalmente os recém-formados, os quais denunciam que a formação não os preparou para os desafios do cotidiano escolar. Paralelamente, a autora argumenta que, nas últimas décadas, as pesquisas do campo da educação têm demonstrado que as escolas exigem o domínio de saberes outros que não apenas aqueles referentes às disciplinas que os professores vão ensinar. Monteiro (2013, p. 29-30) conclui que o modelo de formação ainda vigente, "mais do que formar o profissional professor, tem fortalecido, nos estudantes, o desejo de ser bacharel e pesquisador, e deslegitimado o interesse em ser professor".

Em síntese, os estudos do campo do ensino de história defendem que a formação inicial do historiador deve possibilitar conhecimentos atualizados do campo da historiografia e do campo dos conteúdos "factuais", assim como deve possibilitar a compreensão dos modos de produção do conhecimento histórico. Não obstante, tratando-se de uma formação docente, é necessário que a formação inicial seja encarada como formação do professor, permitindo o desenvolvimento da identidade profissional. Assim, o professor de história deve ser alguém que domine não apenas os mecanismos de produção do conheci- 
mento histórico, mas um conjunto de saberes, competências e habilidades que possibilitem o exercício profissional da docência.

Tendo essa proposição como o objetivo da formação do professor de história, cabe avançar em considerações sobre a avaliação no ensino superior para, em seguida, apresentar algumas ações empreendidas no curso de licenciatura em história da Ufopa.

\section{Avaliação no ensino superior}

Ao longo do século XX, formou-se uma "cultura de avaliação", que não se limita ao campo educacional, estendendo-se às demais atividades sociais e mobilizando os recursos dos estados. No plano da educação, a avaliação vem se constituindo em um campo autônomo nas investigações acerca do currículo e da aprendizagem, afirmando-se a percepção de que é parte do processo de ensino-aprendizagem, tendo, dessa maneira, a função de formar o aluno e de promover a aprendizagem.

Como destacam Maria Roldão e Nuno Ferro (2015), em geral, no ambiente escolar, o tempo divide-se em dois momentos: o período de desenvolvimento dos conteúdos curriculares e o tempo das tarefas avaliativas, como as provas e teses, tradicionalmente aplicadas ao final dos componentes curriculares e que resultam em uma classificação-nota que pontua os ritmos e o percurso escolar do aluno. Tal circunstância tende a abordar os campos do ensinar/ aprender e do avaliar/classificar como duas áreas separadas e, no ambiente universitário, sobressai “o hábito, que tantos de nós vivemos quando alunos, de ir às aulas quando se pode e depois estudar para os exames" (Roldão e Ferro, 2015, p. 573). Todavia, as ideias relativas a uma avaliação mais formativa, comprometida com o aprendizado do aluno, têm, pouco a pouco, ganhado mais atenção nos ambientes educativos e nas investigações sobre o ensino-aprendizagem.

Tradicionalmente, a universidade afirmou-se como instituição de pesquisa, de criação de tecnologias e de sistematização dos conhecimentos, sendo uma das principais detentoras do saber necessário para a formação de profissionais. Como outras características desse modelo tradicional, aparecem o afastamento das demandas sociais e regionais, os currículos seriados, a centralidade do professor, os métodos de ensino predominantemente orais e expositivos, e avaliações voltadas aos conteúdos teóricos. Diante das mudanças vivenciadas na sociedade nas últimas décadas, em especial em termos de acesso à informa- 
ção, esse modelo universitário tem se mostrado insuficiente e inadequado para responder às demandas contemporâneas.

Masetto (2015) considera que a docência universitária colocou sua ênfase no processo de ensino, com uma metodologia centrada na transmissão ou comunicação oral de temas e assuntos selecionados por parte do professor, ou leitura de livros e artigos e sua repetição em sala. Não obstante, ao colocar a ênfase no processo de aprendizagem, as consequências apresentam-se bem diferentes, implicando a mudança na organização curricular, na contratação do corpo docente e na metodologia da aula, tendo a aprendizagem dos alunos como finalidade e ocupação básica da docência (Masetto, 2015, p. 44-51). Nesse contexto, a aula tradicional, expressão do modelo industrial de ensino, tem dado lugar a métodos de ensino alternativos, com base na colaboração, na exploração, na investigação e no fazer. Assim, chega-se a um novo papel do processo de ensinoaprendizagem, pautado pela perspectiva de que, "além de reter informação, o aprendiz necessita ter um papel ativo para significar e compreender essa informação segundo conhecimentos prévios, construir novos conhecimentos e saber aplicá-los em situações concretas" (Valente, 2014, p. 81).

Diante dessa percepção acerca do processo de ensino-aprendizagem e do papel ativo do aluno, a questão da avaliação também passa a ser redimensionada, demarcando-se a necessidade de maior ênfase na construção dos conhecimentos, em vez de centrar a atenção na transmissão de conhecimentos técnicocientíficos de cada componente curricular. Contudo, nas universidades, é comum que os procedimentos deem destaque ao domínio de conceitos científicos e às habilidades profissionais de natureza técnica, e, como demonstram Berbel, Oliveira e Vasconcelos (2006, p. 137), nas licenciaturas essa questão da avaliação torna-se ainda mais delicada, pois os cursos formam professores e, assim, devem "preparar os futuros profissionais no que se refere à avaliação da aprendizagem, bem como possibilitar a eles a vivência de políticas diferenciadas e inovadoras de avaliação”.

A literatura especializada sobre o tema da avaliação no ensino superior tem enfatizado "a importância de se dar mais valor à formação na área de avaliação, já que saber avaliar corretamente é fundamental para o desenvolvimento do ensino", apesar de a maior parcela dos estudos não se concentrar no tema da avaliação durante a formação inicial ou a formação continuada (Boldarine, Barbosa e Annibal, 2017, p. 168, 176). Desse modo, a avaliação ocupa papelchave na formação inicial do professor, mostrando-se um instrumento de aprendizagem e de reflexão sobre o próprio processo de aprendizagem. 
Tendo em vista tais apontamentos sobre a formação inicial do professor de história e sobre o tema da avaliação no ensino superior, passa-se a considerações sobre a experiência docente na licenciatura em história da Ufopa, focando as ações desenvolvidas com o intuito de superar modelos de avaliação classificatória e promover a perspectiva de avaliação como processo capaz de gerar aprendizagem.

\section{A docência em história na Ufopa}

Meu ingresso na Ufopa deu-se em julho de 2014, mediante concurso para as áreas de história antiga e medieval. Anteriormente, havia tido experiências em preparatórios para o vestibular (2006-2011), na educação básica, tanto na rede particular (2009-2013) quanto na rede pública municipal (SME-RJ, 2013-2014), e no ensino superior, por meio do ensino a distância (EaD) em história do Cederj/Unirio. Conforme indicado, ao ingressar na instituição, minha prática docente não se diferenciava muito das práticas criticadas pela literatura, mobilizando mais referências da vida escolar/universitária — o que, segundo Tardif (2000), geralmente é uma constante na prática docente — do que fundamentos pedagógicos. Porém, conciliando as experiências profissionais anteriores com a reflexão acerca da docência no ensino superior, foi possível promover mudanças, que estão em desenvolvimento.

Primeiramente, tais pressupostos redefiniram o planejamento de ensino, e os cursos passaram a se estruturar em torno de eixos transversais - por exemplo, diversidade e interação cultural, processos migratórios, meio ambiente e sociedade, corpo e sociedade, entre outros — , a dar centralidade às discussões relativas ao ensino e às atividades práticas - como a análise de livros didáticos, filmes, animações, quadrinhos, entre outros materiais, para o uso no ensino e a buscar o desenvolvimento de diferentes habilidades e competências na formação dos estudantes - com ênfase no papel do lúdico e da tecnologia na educação. Além disso, aulas que anteriormente estavam centradas no professor e na discussão da bibliografia passaram a enfatizar os alunos, a documentação de diferentes tipologias e a incorporação de elementos práticos e do universo profissional. Desse modo, a mudança manifestou-se no espaço físico da aula e nas interações que ocorrem nele. Uma vez que as aulas expositivas passaram a ser pontuais ao longo da disciplina, o espaço deixou de ser disposto apenas em carteiras enfileiradas, passando a variar conforme as atividades, como a reunião dos alunos em duplas ou pequenos grupos para a resolução de exercícios e a 
análise de documentos em sala, ou com as carteiras colocadas em círculo para debates com base na bibliografia do curso, materiais complementares e em questões norteadoras.

Em relação ao processo de avaliação, inicialmente, procurou-se o afastamento das práticas avaliativas homogeneizadoras que privilegiavam apenas um tipo de desenvolvimento/habilidade do estudante, como as provas discursivas compostas por poucas questões dissertativas acerca da bibliografia e/ou dos conceitos explorados nas disciplinas. Para isso, passei a diversificar as formas de avaliar, explorando a oralidade: seminários, rodas de discussão e exposição de sínteses sobre textos; a escrita: resenhas, fichamentos, artigos, estudos dirigidos e diário reflexivo; e a prática: produção de jogos de tabuleiros, materiais didáticos textuais, podcasts e videocasts, análise de livros didáticos e organização de mostras (festival de teatro grego, mostra de história medieval). Nesse sentido, as mudanças pautaram-se pela diversificação das atividades com uma aprendizagem orientada por práticas colaborativas e de superação da reprodução do conhecimento, além de buscarem aproximar os mecanismos de produção do conhecimento histórico com o conjunto de saberes, competências e habilidades que fundamentam o exercício profissional da docência.

Ademais, por meio desses eixos, procurou-se explorar as sugestões de Selva Fonseca (2003, p. 248) para a prática docente, como: "utilizar diferentes metodologias e tecnologias de ensino de modo a propiciar ao futuro profissional suportes necessários para o exercício da prática docente"; "compreender a avaliação como momento de ensino e aprendizagem, subsídio para o replanejamento das atividades"; e "valorizar todas as dimensões do trabalho pedagógico do professor no contexto escolar".

Com o intuito de contribuir para a leitura e a sistematização dos textos usados nos cursos, a construção de mapas conceituais pelos alunos tem sido produtiva como forma de ensino-aprendizagem, em especial das aulas/unidades teóricas. Eles são orientados a construir os mapas conceituais — que são "diagramas que indicam a relação de conceitos, procurando mostrar as relações entre os conceitos pertinentes à estrutura do conteúdo" (Anastasiou e Alves, 2003, p. 83) — individualmente ou em pequenos grupos, permitindo ao docente observar a compreensão dos conceitos mais importantes, a seleção dos conceitos-chave e a estruturação da teia relacional. Tenho percebido, como pontua Marco Moreira (2010, p. 57), que os mapas conceituais podem ser usados na perspectiva de uma avaliação formativa e recursiva, e oferecem ao docente informações sobre como está se desenvolvendo a aprendizagem do aluno do ponto de vista conceitual, permitindo ainda que o aluno possa refazer, adequar 
e ampliar o mapa à medida que novas compreensões e relações sejam estabelecidas.

Para acompanhar o desenvolvimento individual da aprendizagem dos alunos e favorecer o feedback da disciplina em suas etapas e no todo, tenho trabalhado com diários desde 2017, instrumento didático de avaliação comum nas disciplinas de estágio, mas que demonstra um grande potencial para o acompanhamento da aprendizagem de maneira diversa e processual (Darsie, 1996; André e Pontin, 2010). Nos diários reflexivos, os alunos descrevem reflexões sobre a bibliografia básica e os demais materiais consultados, sobre as dinâmicas de sala e do ambiente virtual, e sobre o trabalho em grupo e a relação com a turma e o professor. O roteiro para a elaboração do diário direciona a reflexão para identificar as dificuldades enfrentadas, a aprendizagem alcançada em cada unidade do curso e as relações entre as discussões da disciplina e as de outros componentes curriculares já cursados, além de estimular a reflexão acerca das contribuições da disciplina para a formação profissional.

Por meio dos diários reflexivos, é possível identificar dificuldades de aprendizagem, verificar o que o aluno aprendeu ou não aprendeu, relacionar os conteúdos aprendidos ao longo da trajetória acadêmica, entre outras potencialidades avaliativas. O diário reflexivo também oferece a possibilidade de o educando construir sua própria percepção do processo, expressando os desafios encontrados no percurso acadêmico, além de ser uma ferramenta que contribui para o contato e a aproximação entre o docente e o discente, mobilizando a construção tanto de um texto acadêmico acerca da bibliografia e dos conceitos dos componentes curriculares quanto de um texto em primeira pessoa, que traz referências pessoais do processo educativo e das experiências de vida.

Nesse sentido, destacam-se três elementos que tem sido possível explorar a partir dos diários reflexivos. Primeiramente, o diário favorece a autoavaliação e a postura reflexiva do aluno, com o estudante refletindo sobre sua aprendizagem e sobre sua trajetória até o momento em questão, identificando potencialidades e necessidades de aperfeiçoamento. Destarte, o diário mostra-se uma metodologia de avaliação que estimula os aspectos dialógico, crítico e emancipador. Em segundo lugar, e diretamente relacionado com o elemento anterior, o diário alcança as diferentes dimensões do desenvolvimento do estudante, com destaque para o elemento afetivo-emocional. Questão por vezes negligenciada no dia a dia da sala de aula e não alcançada pelas avaliações tradicionais, o aspecto afetivo-emocional tem se afirmado como um dos principais desafios do ambiente escolar, em especial do universitário, cada vez mais afetado por problemas de saúde mental, como casos de depressão, crises de ansiedade e suicí- 
dios (La Cruz, 2018). O diário, por permitir a aproximação entre professor e aluno e, principalmente, por favorecer a expressão das individualidades, tem possibilitado identificar casos de depressão, dificuldades na adaptação à vida acadêmica e, em alguns casos, ao contexto de uma nova cidade ou à distância da família. Por fim, o diário tem contribuído para a superação do olhar autocentrado, no qual o estudante apenas acostuma-se a apresentar considerações sobre sua própria experiência de aprendizagem, ao passo que promove uma visão ampliada que alcança as interações ocorridas no ambiente da sala de aula entre o professor e a pluralidade de alunos, a organização do ambiente e o desenvolvimento coletivo. Considera-se que, talvez, esse seja um dos grandes desafios da formação inicial docente, isto é, formar o olhar do futuro professor para explorar as diferentes dimensões e personagens inseridos na sala de aula, construindo sua percepção com base nas coletividades sem descurar das individualidades.

Em linhas gerais, é comum que nas disciplinas pedagógicas os alunos elaborem planos de aula, desenvolvam materiais com finalidade didática e aproximem-se do espaço escolar, esse contato geralmente ocorrendo nos estágios supervisionados. Compreendendo que todos os componentes curriculares devem contribuir para a formação pedagógica, nos cursos de história antiga, história medieval e história moderna tenho trabalhado com livros didáticos de diferentes décadas, revistas, músicas, textos literários, histórias em quadrinhos e filmes, com o objetivo de refletir sobre como esses materiais e essas linguagens podem ser usados no ensino de história. Em termos avaliativos, tenho insistido na análise de livros didáticos no primeiro semestre da graduação, em história antiga, buscando caracterizar a obra em variadas dimensões: autoria, editora, coleção, ano de publicação, ano letivo, estrutura e abordagem. Cabe aos grupos selecionar um capítulo e problematizar a abordagem do livro didático a partir, principalmente, das leituras da disciplina. A atividade tem dado importantes resultados, em especial por possibilitar o primeiro contato acadêmico com os livros didáticos e por favorecer a compreensão da historicidade dos conteúdos e da abordagem dos livros.

Além disso, as ações também têm se concentrado na produção de planos de aula e de jogos didáticos. Em relação ao plano de aula, inicialmente a proposta limitava-se a que os alunos construíssem um plano a partir dos conteúdos da disciplina, incluindo diferentes fontes/linguagens nos planos (jogos, quadrinhos, literatura, vídeos, música, teatro, documentos textuais, imagens, cultura material). Apesar do retorno positivo dessa atividade, passou-se a agregar outros aspectos que potencializaram a avaliação. Por um lado, buscou-se que, juntamente ao plano tradicional, os alunos elaborassem uma aula digital, 
aplicando os elementos do plano escrito. Essa estratégia visou a contribuir para a "educação para as mídias", problematizar a aplicabilidade dos planos e produzir recursos que pudessem ser disponibilizados aos professores da educação básica e ser acessados pelos próprios alunos.

Por outro lado, passou-se a solicitar que os alunos elaborassem os planos de aula voltados para determinada realidade escolar. Para explicar os caminhos que levaram a essa reorientação da atividade, convém um breve relato. Durante a disciplina História Antiga ofertada em 2014, tive dois dias letivos dedicados exclusivamente ao ensino e à produção dos planos de aula. Inicialmente, a aula partiu de uma reflexão textual e buscou discutir os apontamentos do texto com base na trajetória educacional dos alunos, alguns recém-formados no Ensino Médio, afastados dos ambientes de ensino há muitos anos ou em segunda graduação. A atividade foi muito rica, e um dos destaques foi a percepção de que a realidade escolar do município e da região era muito variada, com alunos tendo estudado em escolas bem-estruturadas (públicas e particulares), outros tendo vivenciado problemas crônicos da educação no Brasil (falta de professores, salas lotadas etc.), e alguns tendo recebido sua formação em escolas rurais ribeirinhas, multisseriadas, em comunidades indígenas e quilombolas, o que trouxe novos elementos para a discussão, como a diferença linguística, as disciplinas modulares e a ausência de energia elétrica em algumas escolas. Não obstante, no dia seguinte, os grupos apresentaram seus planos de aula e unanimemente elaboraram aulas com o uso do datashow, ainda que não tenham sido orientados a isso. Ao discutir os trabalhos em sala, uma das questões mais debatidas foi a distância entre os planos e a realidade regional heterogênea apresentada pelos próprios discentes.

Esse breve relato fundamenta a mudança na estruturação da avaliação, pois, a partir dessa experiência, percebi que os alunos permanecem afastados do espaço escolar durante quase toda a graduação — salvo aqueles que participam de projetos como o Pibid e o PET. O contato estabelece-se, geralmente, apenas nos estágios docentes, e, em consequência desse cenário, mesmo atividades voltadas à escola, como a produção de planos de ensino, eram desenvolvidas dentro do meio acadêmico e desligadas da realidade escolar. Dessa maneira, desde 2016, antes de elaborar os planos de aula, tem sido solicitado aos alunos escolher uma escola da rede privada ou da rede pública estadual ou municipal, agendar uma visita ao estabelecimento, desenvolver um relatório diagnóstico e uma entrevista com o professor de história e, a partir desses dados, construir um plano de aula voltado às condições encontradas na escola selecionada. Considerase que a mudança foi muito produtiva, tendo contribuído para aproximar os 
alunos do espaço escolar desde o ingresso na universidade e para explorar a complexidade do exercício profissional. O feedback dos alunos ressaltou ainda a identificação de práticas educativas e de materiais didáticos variados por parte dos professores entrevistados, bem como a motivação para a elaboração de estratégias de ensino distintas conforme as realidades escolares.

Desde 2016, tenho desenvolvido de forma alternada, junto às turmas do segundo e do terceiro semestre do curso de licenciatura em história, durante as disciplinas História Medieval (85 horas) e História Moderna (85 horas), o projeto de produção de jogos educativos como atividade avaliativa final das disciplinas. A atividade baseou-se nas propostas da aprendizagem colaborativa e do ensino com pesquisa, com o objetivo da avaliação sendo a mobilização e a aplicação dos conteúdos aprendidos durante o curso na produção de jogos educativos. Compreende-se que jogos educativos são aqueles que têm objetivo didático explícito e podem ser adotados ou adaptados para melhorar, apoiar ou promover processos de aprendizagem em um contexto de aprendizagem formal ou informal (Dondi e Moretti, 2007 apud Panosso, Sousa e Haydu, 2015, p. 234). Nesse sentido, tanto jogos comerciais quanto jogos desenvolvidos especificamente para a educação são englobados pela categoria dos jogos educacionais.

Os jogos de tabuleiro passam por um momento de ascensão no mercado de entretenimento, com convenções anuais de jogadores e desenvolvedores, sendo um modelo de jogo vantajoso por incentivar a interação social presencial entre os jogadores e por representar uma mídia acessível para desenvolvedores e consumidores, além de serem aqueles mais próximos da utilização em sala de aula, especialmente porque demandam recursos ao alcance da comunidade escolar. Em sua maioria, os jogos educativos dizem respeito ao campo da lógica/matemática e da alfabetização, e, em um segundo plano, há jogos de ciências naturais e de geografia, porém é possível adaptar jogos tradicionais, permitindo uma enorme variedade de modelos e ferramentas em seu desenvolvimento (Dean, 2012 apud Perkoski e Souza, 2015, p. 234; Meinerz, 2013, p. 109). Conforme o levantamento apresentado por Panosso, Sousa e Haydu (2015, p. 234), os estudos atuais sobre jogos nas áreas da educação, da saúde e da biologia apontam diferentes características educacionais dos jogos: eles constituem uma estratégia motivadora a ser usada no ensino; são um recurso que favorece a tomada de consciência dos alunos; favorecem a tomada de decisões; e são um recurso que fornece um ambiente apropriado e diversificado para o aprendizado de habilidades específicas. Além disso, os jogos exigem que os estudantes participem ativamente das situações de ensino; trazem a presença de 
conteúdos acadêmicos mesclados à narrativa; possibilitam juntar lição e avaliação de aprendizagem no mesmo material educativo; e permitem o uso desses materiais em larga escala (Connoly, Stansfield e Boyle, 2009 apud Perkoski e Souza, 2015, p. 234).

Para a elaboração dos jogos, cada grupo de alunos tem ficado responsável pela escolha de um tema relacionado com a Idade Média e a Idade Moderna, variando conforme a disciplina. Seguindo as proposições de Marcello Giacomoni (2013), o trabalho dos grupos tem sido estruturado na definição da temática, dos objetivos, da superfície, da dinâmica, das regras e do layout do jogo. Desde a apresentação da proposta, foi informado aos alunos que o trabalho visava a produzir materiais para serem doados às escolas da rede pública do município. Esse fator motivou os grupos a investir na produção de jogos que pudessem ser jogados por grupos de estudantes ou por turmas inteiras e que pudessem auxiliar na avaliação das disciplinas. Desse modo, foram elaborados jogos de tabuleiro com dinâmica de dados e pergunta e respostas, jogos de perguntas e respostas com a perspectiva inclusiva - com todas as informações transcritas para o braile —, jogos de adivinhação e RPGs. Uma primeira atividade de aplicação e doação dos jogos foi realizada em 2017, na Escola Municipal de Educação Infantil e Ensino Fundamental São Jorge, localizada na comunidade São Jorge, rodovia PA-370, Curuá-Uma, Km 30.

O desenvolvimento de jogos educativos teve consequências positivas em diferentes sentidos. De acordo com o feedback dos alunos, em termos de relações pessoais, o trabalho permitiu a aproximação entre os discentes, promovendo o respeito e a colaboração entre a turma; em relação ao conteúdo, possibilitou o aprofundamento e a compreensão de algumas temáticas, visto que, para a elaboração dos jogos, foi necessário retomar as leituras do curso, pesquisar novos dados e transpor tais elementos de forma didática e clara para o jogo; e, em termos pedagógicos, o trabalho suscitou o debate sobre materiais educativos e estratégias para a inclusão de pessoas com deficiência, sobre a utilização dos jogos e da ludicidade no ensino e, especificamente, no ensino de história, e sobre a possibilidade de o docente desenvolver seus próprios jogos educativos.

Para além da produção de jogos, em duas oportunidades a avaliação final das disciplinas História Antiga (2017.1) e História Medieval (2017.2) consistiu na realização de uma mostra. As atividades foram a culminância de um processo que envolveu os conteúdos teóricos e práticos dos componentes curriculares, a preocupação com promoção de diferentes linguagens no ensino de história, privilegiando o percurso do indivíduo/grupo nas disciplinas para a escolha dos temas e da abordagem, o trabalho colaborativo e, em especial, a expres- 
são extensionista da universidade pelo envolvimento da comunidade e das escolas da cidade. Primeiramente, realizou-se o festival de teatro grego. Partindo da frase de Ariano Suassuna (2010): "Acho que todo professor tem de ter alguma coisa de ator...", distribuíram-se três peças do teatro grego (As vespas, Prometen acorrentado e As troianas) e proporcionaram-se oficinas de introdução ao teatro com o apoio do grupo Iurupari. Os alunos ficaram responsáveis pela adaptação, pela produção do cenário e do figurino, encenando a peça em atividade aberta ao público e entregando um relatório da produção da peça, contendo tanto os procedimentos adotados e a divisão de tarefas quanto a contribuição da atividade para o ensino de história e para a formação profissional do grupo.

O segundo caso foi a mostra de história medieval. Seguiu-se o mesmo padrão, estruturando-se a mostra em forma de exposições e de dramatizações, finalizadas pela entrega de relatório. Assim, foram apresentados trabalhos sobre: o uso de quadrinhos no ensino de história medieval; a literatura medieval e o medievalismo na literatura contemporânea; as séries de televisão e os usos do passado medieval; e sobre a alimentação medieval, reproduzindo um banquete. Além disso, foi produzida uma maquete de cidade medieval dos séculos XII e XIII, encenada uma peça com o tema "Corpo e sexualidade" na Idade Média, e realizada uma apresentação de dança medieval.

As atividades foram bem-sucedidas e mobilizaram as turmas e a comunidade. Todavia, em termos de diagnóstico da aprendizagem, a mostra medieval mostrou-se mais satisfatória, tendo em vista a organização de grupos menores, a avaliação individual durante a atividade e a entrega de relatórios mais detalhados, ao passo que o festival de teatro, conforme o feedback dos alunos, por envolver um número alto de estudantes por grupo (cerca de 20 alunos), prejudicou o envolvimento individual com a totalidade do trabalho e, consequentemente, com as etapas de construção, as quais visavam a demonstrar o potencial pedagógico do teatro.

Acrescenta-se que uma das potencialidades encontradas na elaboração dessas avaliações foi o perfil da turma, que, desde as primeiras aulas, mostrouse disposta a avaliações alternativas e lúdicas, tendo os próprios alunos construído a proposta da mostra medieval como avaliação. Nesse sentido, destaca-se que, em outras turmas, a via da ludicidade não teve a mesma recepção, o que reafirma que a avaliação e as estratégias de ensino-aprendizagem devem ser adequadas ao caso específico de cada grupo de alunos. 


\section{Considerações finais}

Ao acompanhar as discussões da formação em história, observa-se que as pesquisas enfatizam que o professor da disciplina deve ser alguém que domine não apenas os mecanismos de produção do conhecimento histórico, mas um conjunto de saberes, competências e habilidades que possibilitem o exercício profissional da docência. Essa proposição serve de ponto de partida para novas e necessárias reflexões, pois, ao ter como horizonte uma formação que também se estruture no exercício profissional da docência, os cursos de licenciatura tendem a passar por uma reestruturação significativa, como as que direcionam os debates da Base Nacional Comum Curricular. Essa reestruturação não pode ser pensada apenas no campo da história; antes, passa necessariamente pelas discussões do campo da educação e envolve diretamente o problema da aprendizagem e da docência universitária. Nesse sentido, concentrou-se a atenção na questão da avaliação, em especial na perspectiva da avaliação formativa, demonstrando a crescente produção acerca da temática e como os estudos apontam que os processos avaliativos devem estar integrados às ações de ensinoaprendizagem.

A partir das experiências que tenho desenvolvido na Ufopa desde 2014, assinalei meu próprio movimento em busca de superar práticas tradicionais ainda comuns no meio acadêmico e implementar cursos diferenciados. Por meio desse relato de experiência, visou-se a pontuar a redefinição do planejamento de ensino e, principalmente, das avaliações. Alguns exemplos foram citados, mobilizando diferentes metodologias avaliativas com o objetivo de oferecer elementos para, talvez, o leitor refletir sobre e adequar tais ações à sua realidade escolar ou universitária. Não obstante, convém mencionar que tais experiências estão em constante adaptação e reavaliação, considerando-se as limitações observadas em cada turma. Destas, destaca-se o limite dos acordos pedagógicos, posto que alguns alunos demonstram indisposição em relação às avaliações alternativas ou solicitam um retorno às práticas avaliativas tradicionais, como os testes finais e outras atividades que privilegiem apenas a produção escrita.

Em síntese, o interesse foi discutir o desafio imposto à formação inicial do professor de história, demonstrando que essa questão envolve problemáticas específicas do campo disciplinar e problemáticas mais amplas do campo da educação. Não tive a pretensão de apresentar definições muito precisas nem mesmo uma proposta de formação já cristalizada, afinal não tem sido essa nos- 
sa própria realidade. As experiências profissionais em diferentes níveis do ensino têm mostrado a necessidade de constantemente estar atento às novas demandas educacionais e buscar adequar as práticas de ensino-aprendizagem a essas demandas. Deseja-se que os apontamentos apresentados e as vivências compartilhadas possam contribuir para o processo de qualificação da formação de professores e, especificamente, da formação de professores de história.

\section{Referências}

ANASTASIOU, Léa das Graças Camargos; ALVES, Leonir Pessate (org.). Processos de ensinagem na universidade: pressupostos para as estratégias de trabalho em aula. Santa Catarina: Univille, 2003.

ANDRÉ, Marli Eliza Damasco Afonso de; PONTI, Marta Maria Darsie. O diário reflexivo, avaliação e investigação didática. Meta: Avaliação, Rio de Janeiro, v. 2, n. 4, p. 13-30, jan./abr. 2010.

BERBEL, Neusi Aparecida Navas; OLIVEIRA, Cláudia Chueire de; VASCONCELOS, Maura Maria Morita. Práticas avaliativas consideradas positivas por alunos do ensino superior: aspectos didático-pedagógicos. Estudos em Avaliaşão Educacional, v. 17, n. 35, set./dez. 2006.

BOLDARINE, Rosaria de Fátima; BARBOSA, Raquel Lazzari Leite; ANNIBAL, Sérgio Fabiano. Tendências da produção de conhecimento em avaliação das aprendizagens no Brasil (2010-2014). Estudos em Avaliação Educacional, v. 28, n. 67, jan./abr. 2017.

DARSIE, Marta Maria Pontin. Avaliação e aprendizagem. Cadernos de Pesquisa, São Paulo, n. 99, p. 47-59, nov. 1996.

FONSECA, Selva Guimarães. Didática e prática de ensino de história. Campinas: Papirus, 2003.

GIACOMONI, Marcello Paniz. Construindo jogos para o ensino de história. In: GIACOMONI, Marcello Paniz; MULLET, Nilton Pereira. Jogos e ensino de história. Porto Alegre: Evangraf, 2013. p. 118-147.

LA CRUZ, Fernanda. Por que depressão e ansiedade afetam cada vez mais universitários. Desafios da Educação, 30 jul. 2018. Disponível em: < $\underline{\text { https://desafios- }}$ daeducacao.com.br/ansiedade-e-depressao-na-universidade/.> Acesso em: 7 jan. 2019. 
MASETTTO, Marcos T. Competência pedagógica do professor universitário. São Paulo: Summus, 2015.

MEINERZ, Carla Beatriz. Jogar com a história em sala de aula. In: GIACOMONI, Marcello Paniz; MULLET, Nilton Pereira. Jogos e ensino de bistória. Porto Alegre: Evangraf, 2013. p. 99-117.

MONTEIRO, Ana Maria. Formação de professores: entre demandas e projetos. Revista História Hoje, v. 2, n. 3, p. 19-42, 2013.

MOREIRA, Marco Antônio. Mapas conceituais e aprendizagem significativa. São Paulo: Centauro, 2010.

OLIVEIRA, Margarida Maria Dias de; FREITAS, Itamar. Desafios da formação inicial para a docência em história. Revista História Hoje, v. 2, n. 3, p. 131$147,2013$.

PANOSSO, Mariana Gomide; SOUZA, Ś́lvia Regina; HAYDU, Verônica Bender. Características atribuídas a jogos educativos: uma interpretação analíticocomportamental. Revista Quadrimestral da Associação Brasileira de Psicologia Escolar e Educacional, São Paulo, v. 19, n. 2, p. 233-241, maio/ago. 2015.

PERKOSKI, Izadora Ribeiro; SOUZA, Sílvia Regina. “O espião”: uma perspectiva analítico-comportamental do desenvolvimento de jogos educativos de tabuleiro. Revista Perspectivas, v. 6, n. 2, p. 74-88, 2015.

PIMENTA, Selma Garrido; ANASTASIOU, Léa das Graças Camargos. Docência no ensino superior. 5. ed. São Paulo: Cortez, 2014.

ROLDÃO, Maria do Céu; FERRO, Nuno. O que é avaliar? Reconstrução de práticas e conceções de avaliação. Estudos em Avaliação Educacional, v. 26, n. 63, set./dez. 2015.

SUASSUNA, Ariano. Ariano Suassuna: "Todo professor deve ter um pouco de ator". Nova Escola, 22 nov. 2010. Disponível em: < https://novaescola.org.br/ conteudo/939/ariano-suassuna-todo-professor-deve-ter-um-pouco-de-ator. $>$ Acesso em: 7 jan. 2019.

TARDIF, Maurice. Saberes profissionais dos professores e conhecimentos universitários: elementos para uma epistemologia da prática profissional dos professores e suas consequências em relação à formação para o magistério. Revista Brasileira de Educação, n. 13, p. 5-24, jan./abr. 2000. 
VALENTE, José Armando. Blended learning e as mudanças no ensino superior: a proposta de sala de aula invertida. Educar em Revista, Curitiba, edição especial, n. 4, p. 79-97, 2014. 